\title{
CARPOMETACARPAL SUBCHONDRAL CYSTS DUE TO REPETITIVE MOVEMENTS IN SHOEMAKER: A CASE REPORT
}

\author{
STEFANO TONINI, STEFANO M. CANDURA, \\ ANDREA LANFRANCO, and N. VALERIO MENNOIA
}

University of Pavia, Pavia, Italy

Department of Public Health and Neuroscience

Salvatore Maugeri Foundation, Pavia, Italy

\begin{abstract}
Objectives: Subchondral carpometacarpal cysts are classic and almost pathognomonic lesions found in workers using vibrating instruments over prolonged periods of time. Materials and Methods: We present the case of a 53-year-old woman who worked for 30 years sewing shoe uppers, a task which required grasping firmly a pear-shaped handle awl and pushing it through the leather upper and the sole of the shoe, with combined flexion and supination movement of the wrist. After approximately 20 years of working, the patient noted gradual onset of paresthesias in the dominant (right) hand, with increasing difficulty in grasping the awl. Subsequent diagnosis of carpal tunnel syndrome was confirmed by electrophysiologic testing and its surgical release was performed. Nevertheless, hand pain, paresthesias and weakness persisted. Results: Ultrasound of the snuffbox tendons excluded DeQuervain tenosynovitis. Radiographic imaging of the symptomatic hand showed carpometacarpal subchondral cystic formations. Conclusions: In addition to demonstrating the usefulness of radiographic imaging in patients with persistent hand pain post-carpal release, this case is important in illustrating that repetitive movements with high pressure over the palmar carpal area may cause bone cysts, even if the subjects do not use vibrating tools.
\end{abstract}

Key words:

UE-WMSDs, Shoe industry, Wrist, Radiography

\section{INTRODUCTION}

Many clinical and epidemiological studies have shown an increased risk of upper limb disorders due to biomechanical overload, functional stress (typically, repetitive movements) and repeated microtrauma caused by hand tools vibrations [1,2]. The set of these injuries, involving anatomical and functional structures of the upper limb, is defined as hand-arm vibration syndrome, nosological entity characterized by: vascular component, represented by secondary form of Raynaud's phenomenon called
Vibration-induced White Finger (VWF); neurological component, consisting of predominantly sensory peripheral neuropathy with multifocal distribution or one confined to the fingers, whose symptoms are paresthesia, reduced tactile and thermal sensitivity, limited manual dexterity and ability to fine manipulation (thoracic outlet syndrome, carpal tunnel syndrome, Guyon canal syndrome); an osteoarticular component, including chronic-degenerative (predominantly, osteoarthritic and/or inflammatory) lesions of bone and joint segments (tendonitis, tenosynovitis,

Received: July 7, 2011. Accepted: September 08, 2011.

Address reprint requests to S. Tonini, Occupational Medicine Unit, Department of Public Health and Neuroscience, Salvatore Maugeri Foundation, Work and Rehabilitation, IRCCS, Scientific Institute of Pavia, University of Pavia, Via Maugeri, 10, 27100 Pavia, Italy (e-mail: stefano.tonini23@libero.it). 
DeQuervain's disease, trigger finger, Dupuytren's disease, Kienböck's disease, Kohler's disease and bone cysts) [3,4]. Angiopathy and osteoarthropathy are recognized as occupational diseases by the EU Commission (2003/670/CE, Annex I, items 505.01 and 505.02) and by the Italian law (Decree 81/2008, Chapter III, Art. 199 et seq.) [5]. Studies on butchers, tailors and workers employed in assembling and packaging, showed biomechanical and clinical evidence of chronic-degenerative disorders of bone and joints of the upper limb segments, particularly in wrist and elbow, caused by repeated percussion or rotary-percussion movements with hand tools and by low frequency/high amplitude vibrations, in combination with other ergonomic stressors [6,7]. Subchondral carpal cysts and bone vacuoles are anatomo-radiological lesions occasionally found in workers who use vibrating tools for prolonged periods of time; these findings have never been described as a result of repetitive movements in the absence of vibrations [8].

\section{CASE REPORT}

We report the case of a 53-year-old woman, working in shoe factory in Vigevano (an Italian town historically related to the footwear industry), who suffered from cervicobrachialgia, pain and numbness in the right (dominant) hand (the patient underwent surgery for carpal tunnel syndrome); she also reported hypoesthesia in the palm and in the 1st, 2nd and 3rd finger of the same hand.

The woman was admitted to our clinical setting to undergo complete diagnostic procedure. On physical examination of the right hand, thenar eminence atrophy with flattening tendency, marked midcarpal ache, lack of strength in grip and opposition movements in the 1st finger, were detected. This condition, beside interfering with the patient's work capability, led to substantial limitation in performing daily activities: she was not able to button up the clothes, screw caps, do the housework and fully take care of personal hygiene. The patient worked for 30 years as a shoe upper seamstress, using a special



Photo 1. Different types of awls.

awl: a tool like punch with pear-shaped handle holding needle with straight or curved tip, used to make holes for the stitching string that fixes the sole (in leather or rubber shoes) to the upper part of the shoe (Photo 1). This job, carried out also at home, involved keeping seated posture in asymmetrical and dysergonomic position and the execution of repetitive movements (average manufacturing of 35 pairs of shoes/loafers daily): she gripped the awl with the right hand and exercised pressure, pushing down with the base of the palm and exerting strength with the forefinger to direct the string through the hole between the leather and the rubber. Simultaneously, a foot held in tension a strap that stabilized the shoe.

The diagnostic procedure, following an accurate occupational and environmental anamnesis and complete physical examination, continued with:

- electroneurography/electromyography, which revealed relapsed right carpal tunnel syndrome;

- upper limbs ultrasonography, which excluded DeQuervain's disease;

- hands radiography, with detection of, only on the right one, degenerative subchondral carpometacarpal cysts of the trapezium, lunate, capitate, scaphoid and hamate bone (visible as hypertransparent, round and small diameter spots) (Photo 2);

- muscular strength assessment, that evidenced hyposthenia and decreased handgrip strength of the right upper limb, developed after reproducing the work task. 


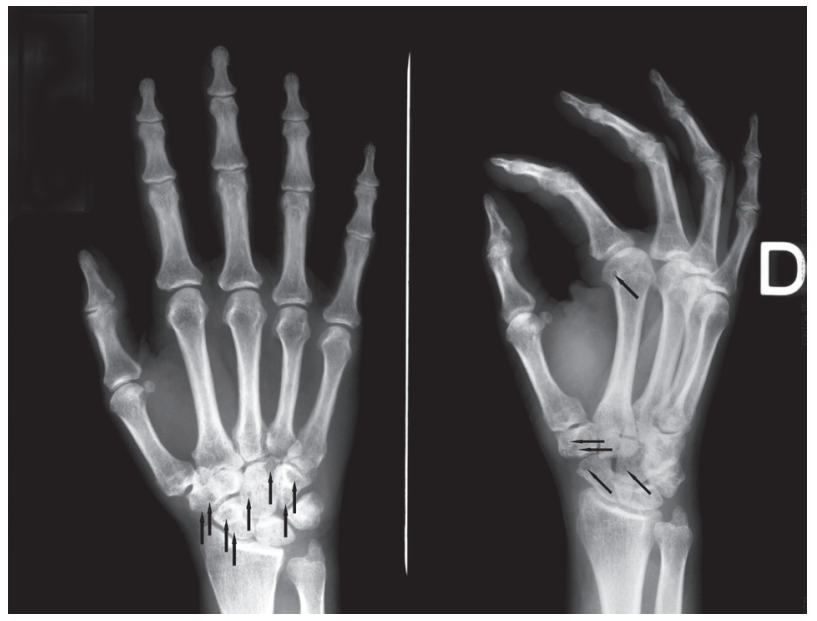

Photo 2. Right hand's radiography that evidences multiple subchondral cysts.

With regard to differential diagnosis, the morphology of the radiological findings and the general clinical picture allowed us to exclude rheumatoid arthritis, osteonecrosis, aneurysmal bone cysts, and local neoplasms (e.g., chondromyxoid fibroma, chondroblastoma, clear cell chondrosarcoma, giant cell tumor of bones).

Recognizing the likely causal relationship between the clinical picture and the occupation, the case was reported to the Judicial Authority (as established by the Italian Penal Code) and was referred to the Italian Workers' Compensation Authority. The patient was advised to avoid any activity requiring repetitive manual movements with or without the use of tools, prolonged incongruous postures and any manual handling of loads heavier than $5 \mathrm{~kg}$. Five months after the examination, the patient opted for retirement.

\section{DISCUSSION}

This is the first report that describes how repetitive movements involving rotation with significant pressure localized on the carpal palmar region may induce the formation of bone cysts even without the use of vibrating devices.

We formulated this new etiological hypothesis thanks to: clinical and instrumental evidences of alterations localized exclusively on the right hand (the hand used at work); the lack of similar evidence in other bones and joints; environmental and occupational history, without familiar history of musculoskeletal disorders of similar nature and in the absence of exposure to vibrations that were not work-related. The job features which, combined in several ways, concurred to determine the clinical condition were: repetitive work tasks, articular overload, intense muscular effort, incongruous postures of the affected joints segments (shoulder, elbow, wrist, hand), and inadequate recovery periods. Additional risk factors were improper execution of the technical act, compression of anatomical structures, dysergonomic work tools, recoil and sudden movement, requirement of high precision and high cadence activities. The pathogenesis of bone cysts (associated with microtrauma or other pathological conditions) is not clearly defined. Two theories have been proposed: (i) the synovial fluid intrusion theory, suggesting that cartilage overload and subsequent degeneration, in association with intraarticular pressure increase, force synovial fluid through focal areas of damaged articular cartilage with secondary resorption of bony trabeculae; (ii) the bony contusion theory, suggesting that the impingement between apposed bone surfaces unprotected by cartilage, in association with vascular insufficiency phenomena, create focus of bone necrosis $[9,10]$.

It could be considered to include the carpometacarpal vacuoles and bone cysts among the UE-WMSDs (Upper Extremity Work-related Musculo-Skeletal Disorders), as related to the same risk factors, such as repetitive handling, repeated flexion-extension movements, and lateral deviation of the wrist or effort during manual tasks $[11,12]$.

\section{REFERENCES}

1. Bovenzi M, Fiorito A, Volpe C. Bone and joint disorders in the upper extremities of chipping and grinding operators. Int Arch Occup Environ Health 1987;59(2):189-98. 
2. Gemne G, Saraste H. Bone and joint pathology in workers using hand-held vibrating tools. An overview. Scand J Work Environ Health 1987;13(4):290-300.

3. Bovenzi M. Hand-transmitted vibration. In: Stellman JM, editor. Encyclopaedia of Occupational Health and Safety. 4th ed. Vol 2, Part IV. Geneva: International Labour Office; 1997. p. 50.7-50.12.

4. Palmer KT, Griffin MJ, Syddall HE, Pannett B, Cooper C, Coggon D. Exposure to hand-transmitted vibration and pain in the neck and upper limbs. Occup Med 2001;51(7):464-67.

5. Commission Recommendation of 19 September 2003 concerning the European schedule of occupational diseases (2003/670/EC). Off J Europ Union L238/28, 25.9.2003.

6. Palmer KT, Harris EC, Coggon D. Compensating occupationally related tenosynovitis and epicondylitis: literature review. Occup Med 2007;57(1):67-74.

7. Bernard BP, editor. Musculoskeletal disorders and workplace factors. Critical review of epidemiologic evidence for workrelated musculoskeletal disorders of the neck, upper extremity, and low back. Cincinnati: US Department of Health and Human Service, National Institute for Occupational Safety and Health; 1997. Publication $N^{\circ} 97-141$.

8. Sluiter JK, Rest KM, Frings-Dresen MH. Criteria document for evaluating the work-relatedness of upper-extremity musculoskeletal disorders. Scand J Work Environ Health 2001;27 Suppl 1:1-102.

9. Landells JW. The bone cysts of osteoarthritis. J Bone Joint Surg 1953;35:643-49.

10. Rhaney K, Lamb DW. The cysts of osteoarthritis of the hip. radiological and pathological study. J Bone Joint Surg 1955;37:663-75.

11. Bazzini G. Aspetti anatomo-funzionali ed inquadramento diagnostico (delle patologie da traumi ripetuti agli arti superiori). G Ital Med Lav Ergon 2001;23:99-104.

12. Violante F, Armstrong T, Kilbom A, editors. Occupational ergonomics work-related musculoskeletal disorders of the upper limb and back. 1st Ed. London, New York: Taylor \& Francis Publishing; 2000.

This work is available in Open Access model and licensed under a Creative Commons Attribution-NonCommercial 3.0 Poland License - http://creativecommons.org/ licenses/by-nc/3.0/pl/deed.en. 